\title{
Surveillance perspective on Lyme borreliosis across the European Union and European Economic Area
}

CC van den Wijngaard ${ }^{1}$, A Hofhuis ${ }^{1}$, M Simões ${ }^{1}$, E Rood ${ }^{2}$, W van Pelt ${ }^{1}$, H Zeller ${ }^{3}$, W Van Bortel 45

1. Epidemiology and Surveillance Unit, Centre for Infectious Disease Control, National Institute for Public Health and the Environment (RIVM), Bilthoven, the Netherlands

2. Epidemiology Unit, KIT (Royal Tropical Institute) Health, Amsterdam, the Netherlands

3. Office of the Chief Scientist, European Centre for Disease Prevention and Control (ECDC), Stockholm, Sweden

4. Surveillance and Response Support Unit, European Centre for Disease Prevention and Control (ECDC), Stockholm, Sweden (affiliation when the work was performed)

5. Institute of Tropical Medicine, Antwerp, Belgium (current affiliation)

\section{Correspondence: Wim Van Bortel (wvanbortel@itg.be)}

van den Wijngaard CC, Hofhuis A, Simões M, Rood E, van Pelt W, Zeller H, Van Bortel W. Surveillance perspective on Lyme borreliosis across the European Union and European Economic Area. Euro Surveill. 2017;22(27):pii=30569. DOI: http://dx.doi.org/10.2807/1560-7917.ES.2017.22.27.30569

Lyme borreliosis (LB) is the most prevalent tick-borne disease in Europe. Erythema migrans (EM), an early, localised skin rash, is its most common presentation. Dissemination of the bacteria can lead to more severe manifestations including skin, neurological, cardiac, musculoskeletal and ocular manifestations. Comparison of LB incidence rates in the European Union (EU)/European Economic Area (EEA) and Balkan countries are difficult in the absence of standardised surveillance and reporting procedures. We explored six surveillance scenarios for LB surveillance in the EU/EEA, based on the following key indicators: (i) erythema migrans, (ii) neuroborreliosis, (iii) all human LB manifestations, (iv) seroprevalence, (v) tick bites, and (vi) infected ticks and reservoir hosts. In our opinion, neuroborreliosis seems most feasible and useful as the standard key indicator, being one of the most frequent severe LB manifestations, with the possibility of a specific case definition. Additional surveillance with erythema migrans as key indicator would add value to the surveillance of neuroborreliosis and lead to a more complete picture of LB epidemiology in the EU/ $\mathrm{EEA}$. The other scenarios have less value as a basis for EU-level surveillance, but can be considered periodically and locally, as they could supply complementary insights.

\section{Introduction}

Lyme borreliosis (LB) is one of the most prevalent vector-borne diseases in Europe. It is caused by Borrelia burgdorferi sensu lato bacteria, which in Europe is transmitted by the tick Ixodes ricinus [1]. Erythema migrans (EM), an expanding skin rash that occurs around the site of the tick bite, is the most common symptom of early LB [1]. It manifests several days to weeks after the tick bite and can be accompanied by influenza-like symptoms such as fever, headache, mild stiff neck, arthralgia and myalgia. If left untreated, dissemination of the bacteria to other tissues can occur and lead to more severe manifestations that include several skin, neurologic, cardiac, musculoskeletal and ocular manifestations [2]. In Europe neuroborreliosis is the most frequent disseminated manifestation, followed by Lyme arthritis, borrelial lymphocytoma, and, more rarely, acrodermatitis chronica atrophicans and Lyme carditis [2]. Early uncomplicated infection generally responds well to antibiotic treatment, and thus the majority of LB patients have a good prognosis. However, even after repeated antibiotic therapy, depending on the initial clinical presentation, a minority of patients report persisting symptoms such as musculoskeletal pain, neurocognitive symptoms and fatigue [1].

There are differences in LB incidence rates and clinical presentations across European countries, which may partly be due to the heterogeneous distribution of Borrelia burgdorferi s.l. genospecies over Europe [3]. Further, the incidence rates of LB across Europe are influenced by geographical, environmental and climatic factors [4-6]. Additionally, human behaviour, including recreational activity, can play a role in LB seasonality [7]. Geographical expansion of the distribution of LB cases has been observed across the European continent [8].

The factors described above are expected to cause true heterogeneity of LB incidence, and thus disease burden, across Europe. However, the heterogeneity found among surveillance systems within Europe complicates the direct comparison of the incidence and trends between countries [9]. LB is a mandatorily notifiable disease in some countries [6]. In countries without mandatory notification, qualified estimates are calculated based on epidemiological studies or incidence 
Surveillance pyramid for Lyme borreliosis and six scenarios for surveillance

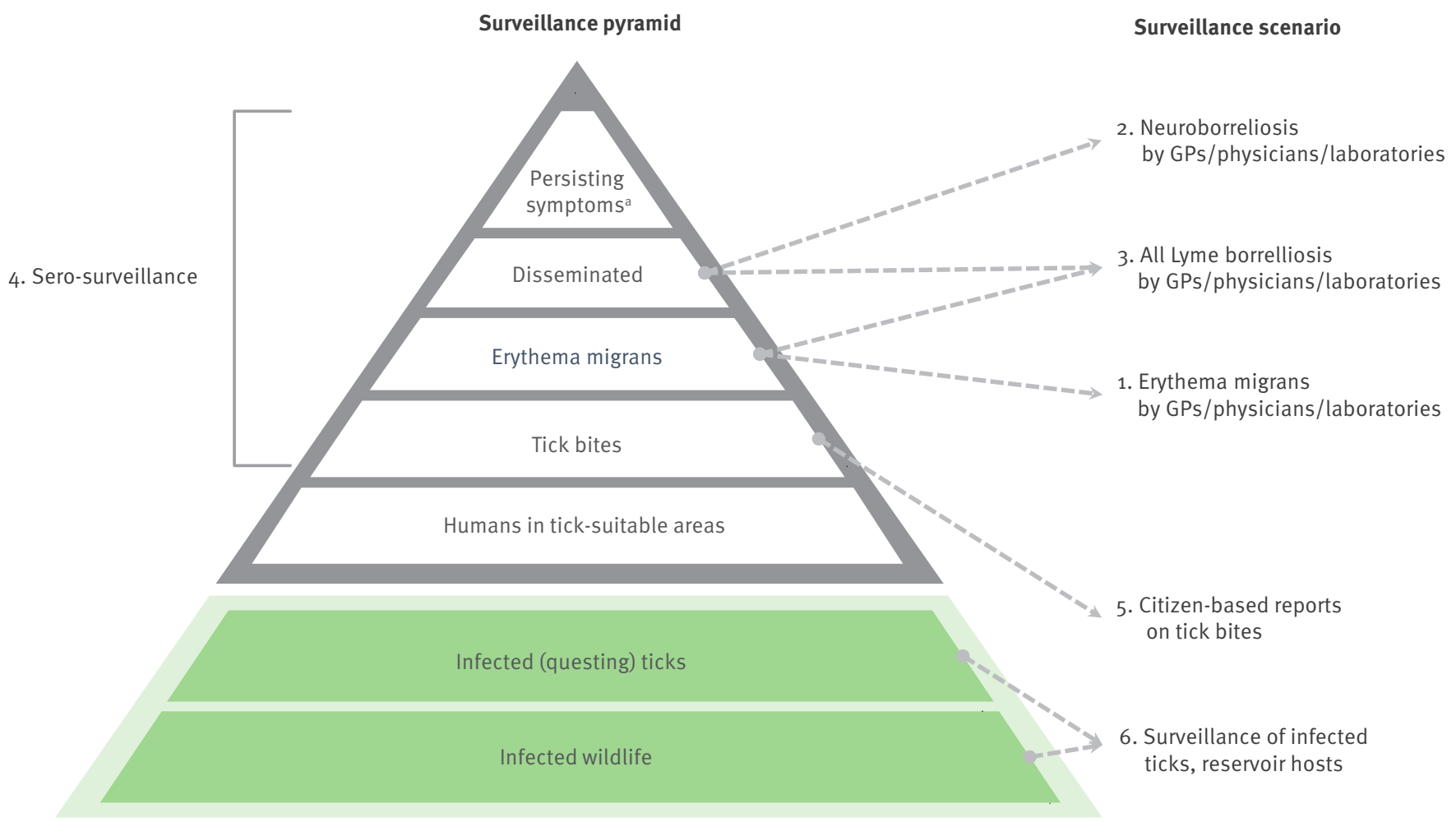

The different levels of the pyramid embody possible key indicators for Lyme borreliosis surveillance.

GPs: general practitioners.

a Persisting symptoms: Lyme borreliosis (LB)-related persisting symptoms (if developed after a documented episode of LB defined as post-Lyme disease syndrome by the Infectious Diseases Society of America [34]) are long-lasting, often severe and sometimes disabling symptoms that physicians and patients attribute to LB. It remains debated to what extent these symptoms are caused by a current or preceding Borrelia infection. Surveillance pyramid adapted from [43].

estimates from neighbouring comparable countries $[2,6]$. Under- and over-reporting, as well as differences in case definitions, diagnostic difficulties and different laboratory methods, are recognised issues for LB diagnosis and surveillance [10]. Furthermore, there are differences in data collection (for instance epidemiological surveys vs laboratory based notification systems), and data collection is often not representative of the whole country (e.g. only high-incidence regions are studied). Accordingly, highly divergent incidence rates for LB have been reported between and within some countries.

The objective of the study presented here is to provide a perspective towards more effective and efficient surveillance of LB in the countries in the European Union (EU) and the European Economic Area (EEA). The acquisition of surveillance data in the EU/EEA is needed to assess the importance of LB there, including assessment of disease burden and cost of illness, and will support the prioritisation of public health resources for the prevention and control of LB. We first define relevant characteristics of the LB surveillance system. Secondly, we propose possible surveillance scenarios building on the surveillance characteristics defined and review their advantages, limitations and requirements.

\section{Surveillance characteristics}

Five characteristics of a surveillance system are considered to assess different LB surveillance scenarios in a structured way: (i) the key indicator(s) (e.g. human LB manifestations) being reported, (ii) the reporting entity (e.g. general practitioners (GPs) and/or hospital physicians or laboratories), (iii) coverage of the surveillance used (comprehensive or sentinel), (iv) type of reporting being implemented (mandatory or voluntary notification), and (v) operational level of the surveillance system (national or regional level).

The value and feasibility of different scenarios as indicated by the levels of the surveillance pyramid in the Figure are explored. Within each scenario, the methods of data collection by the five above-mentioned characteristics of surveillance (Table 1 ) are reviewed, taking 
The five surveillance characteristics considered for the European Union/European Economic Area perspective on Lyme borreliosis surveillance

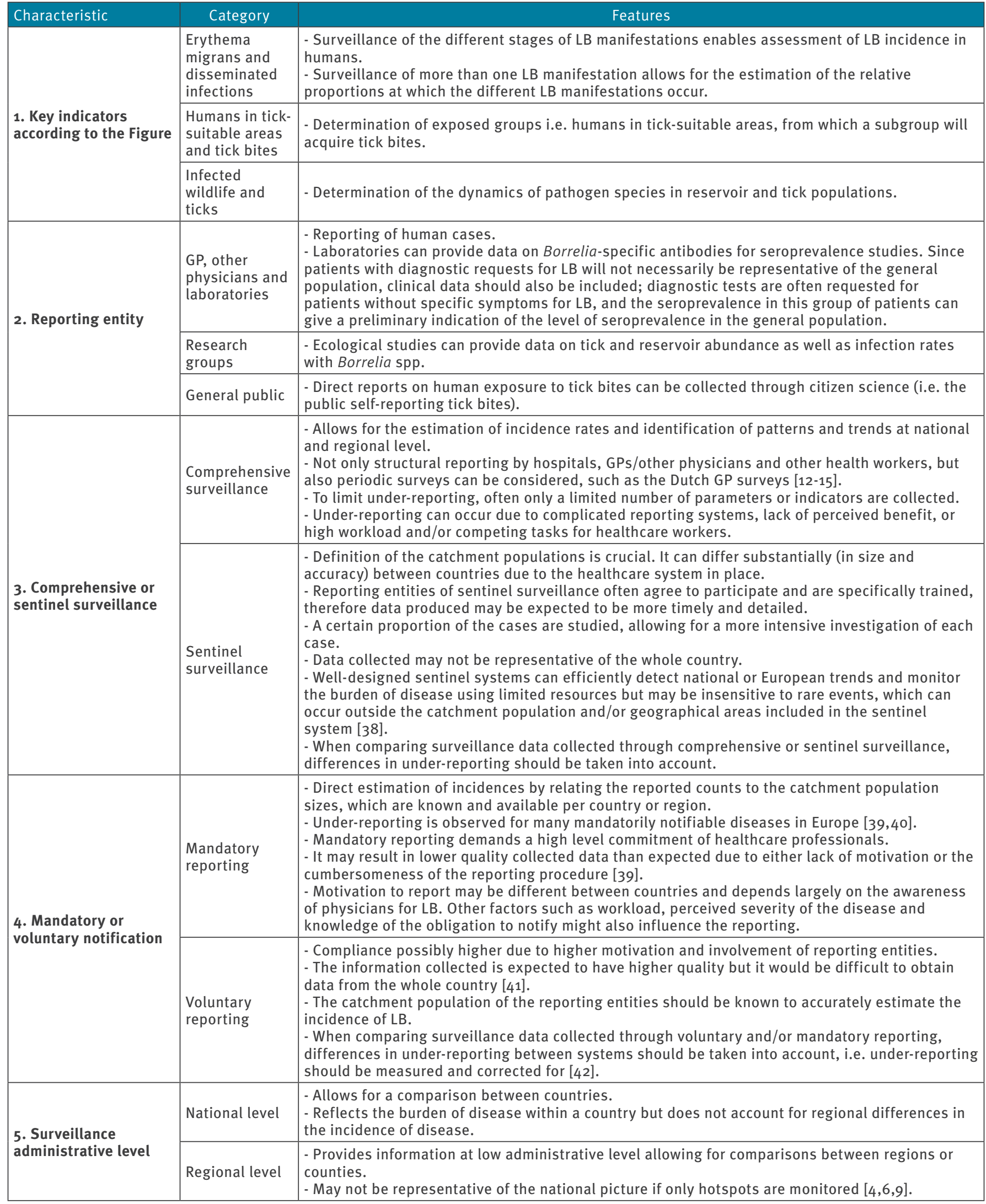

GP: general practitioner; LB: Lyme borreliosis. 
Summary of the main characteristics, advantages, limitations and requirements of the six proposed scenarios for surveillance of Lyme borreliosis across the European Union/European Economic Area

\begin{tabular}{|c|c|c|c|c|c|}
\hline $\begin{array}{l}\text { Surveillance } \\
\text { Scenario }\end{array}$ & $\begin{array}{l}\text { Key indicator for } \\
\text { surveillance }\end{array}$ & $\begin{array}{l}\text { Who is } \\
\text { reporting }\end{array}$ & Advantages & Limitations & Requirements \\
\hline 1 & Erythema migrans & $\begin{array}{c}\text { Hospital } \\
\text { physicians/ } \\
\text { GPs }\end{array}$ & $\begin{array}{c}\text { - Relatively easy recognised } \\
\text { and diagnosed, without } \\
\text { the need for laboratory } \\
\text { confirmation. } \\
\text { - Most common manifestation } \\
\text { of early LB. } \\
\text { - More information on } \\
\text { neuroborreliosis multiplication } \\
\text { factor }{ }^{\text {. }} \text {. }\end{array}$ & $\begin{array}{l}\text { - Motivation to report may be } \\
\text { low for this mild condition. } \\
\text { - Probability of clinically } \\
\text { diagnosing EM may differ } \\
\text { between low- and high- } \\
\text { incidence countries or regions. } \\
\text { - In some countries GP/ } \\
\text { other physicians' catchment } \\
\text { populations may be difficult to } \\
\text { achieve or estimate. }\end{array}$ & $\begin{array}{c}\text { - In each country GPs/other physicians } \\
\text { should be reached and motivated to } \\
\text { report EM cases. } \\
\text { - Accurate administrations of the } \\
\text { names and addresses of GPs/other } \\
\text { physicians would facilitate this } \\
\text { process. } \\
\text { - Communication campaigns can be } \\
\text { launched by national or regional } \\
\text { public health officials. } \\
\text { - In case of not comprehensive } \\
\text { surveillance, for each reporting GP/ } \\
\text { physician their catchment population } \\
\text { needs to be known (or estimated) to } \\
\text { be able to calculate accurate incidence } \\
\text { rates. }\end{array}$ \\
\hline 2 & Neuroborreliosis & $\begin{array}{c}\text { Laboratories } \\
\text { Hospital } \\
\text { physicians/ } \\
\text { GPs }\end{array}$ & $\begin{array}{c}\text { - Precise and standardised } \\
\text { case definition possible, } \\
\text { building upon the EFNS } \\
\text { guidelines [22]. } \\
\text { - One of the most frequent } \\
\text { manifestations of disseminated } \\
\text { LB, and because of its severity } \\
\text { possibly less susceptible to } \\
\text { under-reporting. } \\
\text { - In some countries reporting } \\
\text { based on laboratory } \\
\text { information systems may even } \\
\text { further reduce under-reporting. }\end{array}$ & $\begin{array}{l}\text { - Laboratory diagnostics } \\
\text { on CSF not standard in all } \\
\text { countries. } \\
\text { - Little data on multiplication } \\
\text { factor to other manifestations, } \\
\text { which may differ between } \\
\text { countries because of the } \\
\text { heterogeneous distribution of } \\
\text { Borrelia genospecies }[2-4,22] \text {. } \\
\text { - Less sensitive to trends in } \\
\text { time than EM because of its } \\
\text { lower occurrence rate. }\end{array}$ & $\begin{array}{c}\text { - National and regional laboratories } \\
\text { and/or GPs/other physicians should } \\
\text { be able to report cases based upon } \\
\text { standardised case definitions. } \\
\text { - In case of not comprehensive } \\
\text { surveillance, the catchment } \\
\text { population of the reporting entities } \\
\text { must be known and representative of } \\
\text { the total population. } \\
\text { - Starting by one or a few central } \\
\text { laboratories per country may be } \\
\text { sufficient to have standardised and } \\
\text { comparable data between countries. }\end{array}$ \\
\hline 3 & $\begin{array}{c}\text { All LB } \\
\text { manifestations }\end{array}$ & $\begin{array}{c}\text { Laboratories, } \\
\text { hospital } \\
\text { physicians/ } \\
\text { GPs }\end{array}$ & $\begin{array}{l}\text { } \\
\text { - Incidence estimated for the } \\
\text { complete spectrum of LB. } \\
\text { - Complete information on } \\
\text { neuroborreliosis multiplication } \\
\text { factor. } \\
\text { - Will facilitate assessment of } \\
\text { the disease burden of LB in } \\
\text { DALYs (e.g. healthy life-years } \\
\text { lost), to allow policymakers to } \\
\text { compare the impact of LB with } \\
\text { other (infectious) diseases } \\
\text { [11,31]. }\end{array}$ & $\begin{array}{l}\text { - Surveillance of all LB } \\
\text { manifestations will have a } \\
\text { huge reporting burden. For } \\
\text { countries with a high incidence } \\
\text { of LB, notification of all cases } \\
\text { will not be feasible because } \\
\text { the workload would be too } \\
\text { high for physicians } \\
\text { - Diagnosing the disseminated } \\
\text { manifestations of LB (other } \\
\text { than neuroborreliosis) can } \\
\text { be complicated, resulting in } \\
\text { a high risk of inconsistencies } \\
\text { (and a risk of lack of } \\
\text { specificity) in surveillance } \\
\text { data. } \\
\text { - Standardisation of all LB } \\
\text { manifestations might be } \\
\text { difficult. } \\
\text { - Cumbersomeness of } \\
\text { assessing all laboratory and } \\
\text { clinical criteria per patient may } \\
\text { result in under-reporting. } \\
\text { - High costs will be involved } \\
\text { in training of personnel, } \\
\text { and extensive quality } \\
\text { control would be needed to } \\
\text { guarantee representativeness } \\
\text { and compatibility between } \\
\text { countries. }\end{array}$ & $\begin{array}{l}\text { - In each country GPs/other } \\
\text { physicians, complemented by national } \\
\text { and regional laboratories, should be } \\
\text { reached and motivated to report all } \\
\text { LB cases. } \\
\text { - Accurate administrations of the } \\
\text { names and addresses of GPs/other } \\
\text { physicians would facilitate this } \\
\text { process. } \\
\text { - Communication campaigns can be } \\
\text { launched by national or regional } \\
\text { public-health officials. } \\
\text { - In case of not comprehensive } \\
\text { surveillance, for each reporting GP/ } \\
\text { other physician their catchment } \\
\text { population needs to be known (or } \\
\text { estimated) to be able to calculate } \\
\text { accurate incidence rates. }\end{array}$ \\
\hline
\end{tabular}

DALY: disability-adjusted life year; EFNS: European Federation of Neurological Societies; EM: erythema migrans; GP: general practitioner; LB: Lyme borreliosis.

${ }^{a}$ The factor (or factors) permitting estimation of the incidence of all LB manifestations based on surveillance data from another LB manifestation, e.g. estimate the incidence of neuroborreliosis based upon the incidence of EM.

${ }^{b}$ VectorNet is a joint initiative of the European Food Safety Authority (EFSA) and the European Centre for Disease Prevention and Control (ECDC). The project supports the collection of data on vectors related to both animal and human health in Europe and the Mediterranean basin: http://ecdc.europa.eu/en/ healthtopics/vectors/VectorNet/Pages/VectorNet.aspx

into consideration the ease and reliability of the data collection required. These scenarios can be used to make recommendations on the requirements for effective surveillance of LB across Europe. Table 2 reviews the main advantages and limitations of each scenario based upon our assessment.

\section{Surveillance scenarios}

Scenario 1: Erythema migrans as key indicator $E M$ is the most common manifestation of LB, and the only manifestation in which the clinical symptoms are characteristic of the disease, although not all cases of 
Summary of the main characteristics, advantages, limitations and requirements of the six proposed scenarios for surveillance of Lyme borreliosis across the European Union/European Economic Area

\begin{tabular}{|c|c|c|c|c|c|}
\hline $\begin{array}{l}\text { Surveillance } \\
\text { Scenario }\end{array}$ & $\begin{array}{l}\text { Key indicator for } \\
\text { surveillance }\end{array}$ & $\begin{array}{l}\text { Who is } \\
\text { reporting }\end{array}$ & Advantages & Limitations & Requirements \\
\hline 4 & Seroprevalence & $\begin{array}{l}\text { Population- } \\
\text { based studies, } \\
\text { laboratories, } \\
\text { GPs }\end{array}$ & $\begin{array}{c}\text { - No under-reporting because } \\
\text { seroprevalence studies are } \\
\text { not dependent on reporting } \\
\text { by other entities than } \\
\text { laboratories. } \\
\text { - Standardisation of laboratory } \\
\text { criteria possible in a } \\
\text { prospective setting. } \\
\text { - Seroprevalence studies } \\
\text { provide additional } \\
\text { epidemiological data, such } \\
\text { as information on risk factors } \\
\text { and spatial patterns that can } \\
\text { be used to complement data } \\
\text { from other notification systems } \\
{[17,28] \text {. }}\end{array}$ & $\begin{array}{l}\text { - Only seroprevalence } \\
\text { (historical exposure) can be } \\
\text { measured, and no data on } \\
\text { the incidence of LB (active } \\
\text { infection) can be derived. } \\
\text { - Neither new cases that have } \\
\text { emerged recently nor the } \\
\text { real disease burden can be } \\
\text { assessed through such studies } \\
\text { [27]. } \\
\text { - In a prospective setting, a } \\
\text { complete and representative } \\
\text { sampling for this purpose can } \\
\text { be expensive. } \\
\text { - Different serological tests are } \\
\text { available targeting different } \\
\text { antibodies and having } \\
\text { different sensitivities and } \\
\text { specificities. Standardisation } \\
\text { among countries is needed if } \\
\text { inter-country comparisons is } \\
\text { aimed for. }\end{array}$ & $\begin{array}{c}\text { - Careful design of a seroprevalence } \\
\text { study is required to obtain a } \\
\text { representative sample of all regions of } \\
\text { the country. } \\
\text { - There is the need to clearly define } \\
\text { and standardise the laboratory } \\
\text { methodology and criteria across } \\
\text { countries for comparability. }\end{array}$ \\
\hline 5 & Tick bites & General public & $\begin{array}{l}\text { - Hotspots of human } \\
\text { exposure to tick bites can be } \\
\text { detected with relatively high } \\
\text { sensitivity, which can be used } \\
\text { to steer regional intervention } \\
\text { strategies. } \\
\text { - National and regional } \\
\text { communication campaigns } \\
\text { will improve awareness of the } \\
\text { public and physicians of LB. } \\
\text { - Characteristics of hotspots } \\
\text { can also be compared between } \\
\text { countries, and be used as } \\
\text { input in a knowledge-based } \\
\text { European risk map. }\end{array}$ & $\begin{array}{c}\text { - Awareness and education } \\
\text { of the public is needed to } \\
\text { generate a sufficient report } \\
\text { rate of tick bites. } \\
\text { - The number of tick bite } \\
\text { reports over time will be } \\
\text { influenced by media attention } \\
\text { and thus not always accurately } \\
\text { reflect temporal trends of tick } \\
\text { bites or LB. } \\
\text { - Media attention for online } \\
\text { reporting of tick bites will } \\
\text { differ between countries, } \\
\text { which will complicate } \\
\text { quantitative comparison } \\
\text { between countries. }\end{array}$ & $\begin{array}{l}\text { - Public awareness of the risk for LB } \\
\text { is needed as a motivation to report } \\
\text { tick bites, which requires national and } \\
\text { regional media campaigns to inform } \\
\text { the public about online reporting. } \\
\text { - Communication of the results is } \\
\text { needed to inform and motivate the } \\
\text { participants. }\end{array}$ \\
\hline 6 & $\begin{array}{c}\text { Tick or reservoir } \\
\text { hosts Borrelia } \\
\text { prevalence }\end{array}$ & $\begin{array}{l}\text { Research } \\
\text { groups }\end{array}$ & $\begin{array}{l}\text { - Complementary to human LB } \\
\text { surveillance. } \\
\text { - Results would improve the } \\
\text { prospective surveillance } \\
\text { of LB by providing more } \\
\text { insight on the ecological and } \\
\text { epidemiological features of LB. } \\
\text { - Periodic research studies } \\
\text { are already standard in many } \\
\text { countries. }\end{array}$ & $\begin{array}{c}\text { - It is a complicated process } \\
\text { to timely collect catchment } \\
\text { data with substantial coverage } \\
\text { in a relatively standardised } \\
\text { manner. } \\
\text { - Data on the tick/reservoir } \\
\text { Borrelia prevalence is not } \\
\text { necessarily associated with the } \\
\text { number of LB cases in humans. } \\
\text { - Newly invaded tick areas may } \\
\text { be missed. These possibly } \\
\text { contribute more to increased } \\
\text { tick bite risk than established } \\
\text { catchment areas and will have } \\
\text { a different temporal trend. }\end{array}$ & $\begin{array}{c}\text { - A European network is needed to } \\
\text { standardise sampling and collection } \\
\text { protocols and to gather national } \\
\text { catchment data on ticks and reservoirs } \\
\text { from the national and regional } \\
\text { networks that already perform such } \\
\text { surveillance. } \\
\text { - VectorNet }{ }^{\mathrm{b}} \text { could possibly facilitate } \\
\text { future integration and comparison of } \\
\text { these data [33]. } \\
\text { - It has already been shown that } \\
\text { based on the currently available data } \\
\text { in published literature space and } \\
\text { time trends of infected tick can be } \\
\text { assessed. }\end{array}$ \\
\hline
\end{tabular}

DALY: disability-adjusted life year; EFNS: European Federation of Neurological Societies; EM: erythema migrans; GP: general practitioner; LB: Lyme borreliosis.

a The factor (or factors) permitting estimation of the incidence of all LB manifestations based on surveillance data from another LB manifestation, e.g. estimate the incidence of neuroborreliosis based upon the incidence of EM.

${ }^{b}$ VectorNet is a joint initiative of the European Food Safety Authority (EFSA) and the European Centre for Disease Prevention and Control (ECDC). The project supports the collection of data on vectors related to both animal and human health in Europe and the Mediterranean basin: http://ecdc.europa.eu/en/ healthtopics/vectors/VectorNet/Pages/VectorNet.aspx

EM will be diagnosed, especially not if cases present with an atypical skin lesion [2]. It can be monitored through GPs and/or other physicians reporting clinical EM diagnoses, without the need for laboratory confirmation or interpretation (Table 2). Data can be collected through repeated cross-sectional retrospective surveys, as has been implemented in the Netherlands and some other countries by means of GP surveys [5,11-15]. Other options would be implementation through prospective or retrospective sentinels among hospitals and GP practices [16-18]. These options work mainly on a voluntary basis and are shown to provide high response rates and good regional and national estimates to identify temporal and spatial trends [12]. A nationwide approach would be preferable, including, if possible, regional data collection to identify regional LB transmission hotspots.

Scenario 2: Neuroborreliosis as key indicator Neuroborreliosis is one of the most frequent manifestations of disseminated LB $[2,19]$. Mandatory reporting 
of neuroborreliosis is already common practice in some countries $[6,9,17,19-21]$.

According to the European Federation of the Neurological Societies (EFNS) guidelines for confirmed cases, neurological symptoms have to be laboratory-confirmed by cerebrospinal fluid (CSF) pleocytosis and intrathecal specific antibody production [22]. Compliance with this set of laboratory criteria can, however, be cumbersome. For instance, the Danish microbiology database (MiBa) for neuroborreliosis does not include information on pleocytosis, and, with cases defined as individuals with intrathecal specific antibody production, had a higher capture rate of cases and a more timely data collection than the mandatory notification system in Denmark [20]. Therefore, it may be advisable to allow some levels of confidence for case classification: e.g. possible/probable/confirmed cases. Some countries already use such case classification [23]. In countries where electronic laboratory reporting systems are available, implementation of nationwide laboratory surveillance for neuroborreliosis could be feasible.

Surveillance can also be based on reporting by physicians, especially in countries where testing of CSF is not standard and/or laboratory information systems do not facilitate reporting. However, the information collected in this way will need to be interpreted with caution due to uncertainties in the diagnosis and comparability between countries.

At lower administrative levels or in a sentinel setting, surveillance of neuroborreliosis may be relatively insensitive, since neuroborreliosis is a relatively rare outcome compared with EM, occurring in $3-38 \%$ of LB cases, whereas EM occurs in $60-95 \%$ of all diagnosed LB manifestations $[11,16,17,24]$ (Table 2).

\section{Scenario 3: All manifestations of Lyme}

borreliosis as key indicator

Manifestations other than EM and neuroborreliosis are often more difficult to diagnose. If implemented in a surveillance system, case definitions should be based both on clinical and laboratory diagnostic criteria $[2,25]$. Data collection can be performed through reporting GPs or other physicians and complemented by laboratory reporting e.g $[5,11,16]$. Nationwide and comprehensive surveillance systems, when compared with regional and sentinel approaches, will provide better information on the proportion of the occurrence of each LB manifestation (Table 2). The reporting entities can be invited to participate voluntarily in such surveillance; mandatory reporting of all LB cases may result in under-reporting, especially if GPs and other physicians are requested to include specific laboratory criteria in their assessment of possible cases $[10,26,27]$. For countries with a high incidence of LB, notification of all cases is not feasible because the workload may be too high for physicians and public health authorities.
Scenario 4: Seroprevalence as key indicator Seroprevalence studies for Borrelia-specific antibodies can be conducted at population level, either by using biobanks or blood donors' samples or by collecting samples prospectively. These studies can be performed nationally, to give an overall picture of the exposure to Borrelia within the country and allow for comparison with other EU countries if standard laboratory methods are used (Table 2). Laboratories can also be motivated to supply available laboratory datasets on tests carried out for diagnostic purposes, to give a first indication about the possible seroprevalence in a country, especially if clinical data is available as well. Nevertheless, for a valid estimate of the seroprevalence in a country or region specifically designed seroprevalence studies are needed on a representative sample of the general population. During such studies additional epidemiological data can also be collected, such as information on risk factors and spatial patterns, which complement the data from other notification systems $[17,28]$. However, the data reveal a cumulative incidence proportion of exposure to $B$. burgdorferi s.l. and not the incidence of new disease [28].

Scenario 5: Reported tick bites as key indicator The spatial distribution of tick bites might reflect human exposure to the risk of LB. A relatively new approach for such spatial surveillance is online citizenbased reporting of tick bites, as has been implemented e.g. in the Netherlands from 2006 to 2011 through www.natuurkalender.nl, and since 2012 through www. tekenradar.nl, in Belgium through TekenNet https:// tekennet.wiv-isp.be/ or in Switzerland through https:// zecke-tique-tick.ch/en/tickbite-map-switzerland/. A similar follow-up of hotspots where people have greatest exposure to infected ticks can be implemented in other European countries (Table 2). In addition, regional infection rates of ticks removed from humans can be obtained by having the ticks sent to national laboratories. Furthermore, the risk of and risk factors for LB after a tick bite can be assessed by online follow-up of participants to report subsequent development of LB. This is preferably followed by confirmation of the LB diagnosis through the diagnosing physician. Such prospective studies can be temporarily added to complement routine surveillance.

\section{Scenario 6: Infected tick/reservoir hosts as key indicator}

Europe-wide surveillance and/or studies of tick or reservoir could be complementary to human LB surveillance. Periodic (e.g. monthly) catchment data on ticks and reservoirs can be collected as standardised as possible to derive their prevalence of occurrence and Borrelia spp. infection rates (Table 2). Results would improve prospective surveillance of LB in the focus area by providing more insight into the ecological and epidemiological features of LB and allows identification of the different genospecies circulating in an area $[17,29,30]$. 


\section{Conclusions}

To facilitate better assessment of temporal and spatial trends of LB incidence in Europe, a more standardised surveillance and reporting procedures of $L B$ is required. Priority should be given to standardisation of the key indicators that are put under surveillance between EU countries.

Neuroborreliosis surveillance (scenario 2) across the EU/EEA seems the most feasible and useful scenario, as neuroboreliosis is one of the most frequent severe manifestations. The implementation of a standardised EU case definition is feasible from an operational perspective. Nevertheless, consensus on a standardised case definition is needed between the EU/EEA countries, possibly with some levels of confidence for case classifications e.g. probable/confirmed cases because of difficulties in complying with the laboratory criteria. Surveillance of neuroborreliosis across the EU/EEA will allow for a more accurate assessment of temporal and spatial trends, and the epidemiological features and disease burden of neuroborreliosis. Although complete standardisation would, in theory, lead to the highest comparability of surveillance data, it is probably not feasible to standardise all characteristics of surveillance over all EU/EEA countries. Depending on the country, it will be feasible and cost-efficient to implement surveillance through: (i) laboratory information systems or GPs/other physicians; (ii) comprehensive or sentinel surveillance, although the latter might not be sensitive enough; (iii) mandatory or voluntary reporting, and/or (iv) regional or national reporting. This heterogeneity of feasible surveillance characteristics is caused by dissimilarities in healthcare data logistics (e.g. presence or absence of a national laboratory information system that can be used to detect cases; presence or absence of representative GP sentinels) and the different structures of countries' healthcare systems (e.g. presence or absence of an exclusive role for GPs for all primary care). Based on the abovementioned surveillance characteristics, each country should consider how best to achieve valid neuroborreliosis incidence reports that meet EU-wide surveillance criteria. Internal validation studies should be periodically conducted to assess and correct for under- and over-reporting, to allow comparison between countries.

In addition to surveillance of neuroborreliosis, countries can consider surveillance of EM (scenario 1), depending on the local feasibility of implementation. EM comprises a relatively simple diagnosis with no laboratory confirmation needed and can be easily reported by physicians. Nevertheless, also for EM surveillance, the above-mentioned differences in healthcare system and data logistics should be taken into account; e.g. in countries where GPs have an exclusive role in primary care, surveillance of EM can be based on GP sentinels or surveys, whereas in other countries other physicians should also be included in surveillance. The key advantage of surveillance of both EM and neuroborreliosis is that it allows estimation of country-specific multiplication factors between these manifestations, which may discern effects of the Borrelia genospecies prevalence on the relative proportions of neuroborreliosis and EM. This may lead to a much closer and more complete picture of the epidemiology and disease burden of LB, and a higher sensitivity for temporal and spatial trends.

Reporting of all LB manifestations and seroprevalence studies (scenarios 3 and 4, respectively) does not seem feasible or effective as a form of permanent surveillance. Nevertheless, periodic seroprevalence studies, despite the limitations observed, can be used to relate human exposure to the incidence of LB [28]. To limit the costs, these should be incorporated into (international) seroprevalence studies of other infectious diseases. Furthermore, there would be additional value in assessing the relative proportions of all LB manifestations with a periodicity of e.g. 5-10 years within each country or region [11]. These relative proportions can be used to derive multiplication factors to estimate the incidence of all LB manifestations based upon the permanent neuroborreliosis and/or EM surveillance data. Such incidence estimates of the complete range of LB manifestations would also facilitate expressing the disease burden of LB in disability-adjusted life years (DALYs) (e.g. healthy life-years lost), and cost-of-illness, to allow policymakers to compare with other infectious and non-infectious diseases $[11,31,32]$.

Additional sources of information can be citizen-based reporting of tick bites and surveillance and/or studies of tick abundance and infection rates. Tick data can be periodically analysed to derive temporal and spatial trends of tick abundance and infection rates (scenario 6). The online reporting of tick bites in the Netherlands has revealed spatial and seasonal patterns of human exposure to tick bites (scenario 5). VectorNet, the joint initiative of the European Food Safety Authority (EFSA) and the European Centre for Disease Prevention and Control (ECDC) that supports the collection of data on vectors related to both animal and human health in Europe and the Mediterranean basin, could possibly facilitate future integration and comparison of data on tick abundance and seasonality [33].

LB-related persisting symptoms (if developed after a documented episode of LB defined as post-Lyme disease syndrome by the Infectious Diseases Society of America [34]) is a growing concern, underlined by a survey in the Netherlands where annual incidence was estimated at 5.5 new cases per 100,000 population in 2010 , and disease burden at $86 \%$ of the total burden due to $L B[11,31]$. It concerns long-lasting, often severe and sometimes disabling symptoms that physicians and patients attribute to LB [34]. However, it remains debated to what extent these symptoms are caused by a current or preceding Borrelia infection [2,35,36]. As a result, routine surveillance of the syndrome would not provide accurate and reliable data on which response actions can be designed, which is the reason why this 
is not included as a scenario. Specific studies should first provide more insight into the mechanisms that cause these persisting symptoms $[36,37]$.

In conclusion, surveillance of Lyme neuroborreliosis seems to be the most appropriate way to initiate LB surveillance in the EU despite difficulties to comply with the laboratory criteria. Additional surveillance or specific surveys of the incidence of EM would be of great added value and could possibly be undertaken in sentinel sites. Surveillance and monitoring of the other key indicators would lead to an even more complete picture of temporal and spatial trends, epidemiological features and disease burden of LB, but are more appropriate for specific surveys than for routine surveillance.

\section{Acknowledgements}

This paper is an outcome of the project 'Spatial and temporal trends of LB in the EU and surveillance perspectives' (Framework contract reference: ECDC/2013/016 - European Centre for Disease Prevention and Control (ECDC) tender to assess). This perspective has been presented and discussed during an Expert Network consultation meeting on Lyme borreliosis surveillance in the European Union, in January 2016 in Stockholm. The authors are grateful to the meeting participants for the opinions and views presented during this meeting.

\section{Conflict of interest}

None declared.

\section{Authors' contributions}

Cees (C.C.) van den Wijngaard coordinated the study, collected information and literature, drafted the initial draft of the manuscript and reviewed final document for accuracy.

Agnetha Hofhuis collected information and literature, and reviewed drafts of the manuscript.

Mariana Simões collected information and literature, contributed to the initial manuscript, and reviewed drafts of the manuscript.

Ente Rood reviewed and contributed to drafts of the manuscript.

Wilfrid van Pelt reviewed and contributed to drafts of the manuscript.

Herve Zeller reviewed and contributed to drafts of the manuscript.

Wim Van Bortel initiated the study, drafted the manuscript and reviewed the final document for accuracy.

\section{References}

1. Stanek G, Wormser GP, Gray J, Strle F. Lyme borreliosis.Lancet. 2012;379(9814):461-73. DOI: 10.1016/S0140-6736(11)60103-7 PMID: 21903253

2. Stanek G, Fingerle V, Hunfeld KP, Jaulhac B, Kaiser R, Krause $A$, et al. Lyme borreliosis: clinical case definitions for diagnosis and management in Europe. Clin Microbiol Infect. 2011;17(1):69-79. DOI: 10.1111/j.1469-0691.2010.03175.x PMID: 20132258

3. van Dam AP, Kuiper H, Vos K, Widjojokusumo A, de Jongh BM, Spanjaard L, et al. Different genospecies of Borrelia burgdorferi are associated with distinct clinical manifestations of Lyme borreliosis. Clin Infect Dis. 1993;17(4):708-17. DOI: 10.1093/clinids/17.4.708 PMID: 7903558

4. Lindgren E, Jaenson TGT. Lyme borreliosis in Europe: influences of climate and climate change, epidemiology, ecology and adaptation measures. Copenhagen: World Health Organization Europe; 2006. Available from: http://www.euro.who.int/_ data/assets/pdf_file/ooo6/96819/E89522.pdf

5. Cimmino MA. Relative frequency of Lyme borreliosis and of its clinical manifestations in Europe. European Community Concerted Action on Risk Assessment in Lyme Borreliosis. Infection. 1998;26(5):298-300. DOI: 10.1007/BF02962251 PMID: 9795788

6. Hubálek Z. Epidemiology of lyme borreliosis.Curr Probl Dermatol. 2009;37:31-50. DOI: 10.1159/000213069 PMID: 19367096

7. Dobson AD, Taylor JL, Randolph SE. Tick (Ixodes ricinus) abundance and seasonality at recreational sites in the UK hazards in relation to fine-scale habitat types revealed by complementary sampling methods.Ticks Tick Borne Dis. 2011;2(2):67-74. DOI: 10.1016/j.ttbdis.2011.03.002 PMID: 21771540

8. Medlock JM, Hansford KM, Bormane A, Derdakova M, EstradaPeña A, George JC, et al. Driving forces for changes in geographical distribution of Ixodes ricinus ticks in Europe. Parasit Vectors. 2013;6(1):1. DOI: 10.1186/1756-3305-6-1 PMID: 23281838

9. Smith R, Takkinen J. Lyme borreliosis: Europe-wide coordinated surveillance and action needed?Euro Surveill. 2006;11(6):E060622.1.PMID: 16819127

10. European Centre for Disease Prevention and Control (ECDC). Meeting report. Second expert consultation on tick-borne diseases with emphasis on Lyme borreliosis and tick-borne encephalitis: Stockholm, Sweden, 22-23 November 2011. Stockholm: ECDC; 2012. Available from: http://www.ecdc. europa.eu/en/publications/Publications/Tick-borne-diseasesmeeting-report.pdf

11. Hofhuis A, Harms M, Bennema S, van den Wijngaard CC, van Pelt W. Physician reported incidence of early and late Lyme borreliosis.Parasit Vectors. 2015;8(1):161. DOI: 10.1186/S13071015-0777-6 PMID: 25889086

12. Hofhuis A, Harms M, van den Wijngaard C, Sprong $H$, van Pelt W. Continuing increase of tick bites and Lyme disease between 1994 and 2009.Ticks Tick Borne Dis. 2015;6(1):69-74. DOI: 10.1016/j.ttbdis.2014.09.006 PMID: 25448421

13. Hofhuis A, van der Giessen JW, Borgsteede FH, Wielinga PR, Notermans DW, van Pelt W. Lyme borreliosis in the Netherlands: strong increase in GP consultations and hospital admissions in past 10 years.Euro Surveill. 2006;11(6):E060622.2.PMID: 16819128

14. den Boon S, Schellekens JF, Schouls LM, Suijkerbuijk AW, Docters van Leeuwen B, van Pelt W. Verdubbeling van het aantal consulten voor tekenbeten en Lyme-borreliose in de huisartsenpraktijk in Nederland. [Doubling of the number of cases of tick bites and lyme borreliosis seen by general practitioners in the Netherlands].Ned Tijdschr Geneeskd. 2004;148(14):665-70. Dutch.PMID: 15106318

15. de Mik EL, van Pelt W, Docters-van Leeuwen BD, van der Veen A, Schellekens JF, Borgdorff MW. The geographical distribution of tick bites and erythema migrans in general practice in The Netherlands.Int J Epidemiol. 1997;26(2):451-7. DOI: 10.1093/ ije/26.2.451 PMID: 9169184

16. Vandenesch A, Turbelin C, Couturier E, Arena C, Jaulhac $B$, Ferquel $E$, et al. Incidence and hospitalisation rates of Lyme borreliosis, France, 2004 to 2012. Euro Surveill. 2014;19(34):20883. DOI: 10.2807/1560-7917. ES2014.19.34.20883 PMID: 25188613

17. Wilking $\mathrm{H}$, Stark K. Trends in surveillance data of human Lyme borreliosis from six federal states in eastern Germany, 20092012.Ticks Tick Borne Dis. 2014;5(3):219-24. DOI: 10.1016/j. ttbdis.2013.10.010 PMID: 24656810

18. Vanthomme K, Bossuyt N, Boffin N, Van Casteren V. Incidence and management of presumption of Lyme borreliosis in Belgium: recent data from the sentinel network of general practitioners. Eur J Clin Microbiol Infect Dis. 2012;31(9):238590. DOI: 10.1007/S10096-012-1580-3 PMID: 22391757

19. Christova I, Komitova R. Clinical and epidemiological features of Lyme borreliosis in Bulgaria.Wien Klin Wochenschr. 2004;116(1-2):42-6. DOI: 10.1007/BF03040423 PMID: 15030123

20. Dessau RB, Espenhain L, Mølbak K, Krause TG, Voldstedlund M. Improving national surveillance of Lyme 
neuroborreliosis in Denmark through electronic reporting of specific antibody index testing from 2010 to 2012 Euro Surveill. 2015;20(28):21184. DOI: 10.2807/1560-7917. ES2015.20.28.21184 PMID: 26212143

21. Lopes de Carvalho I, Núncio MS. Laboratory diagnosis of Lyme borreliosis at the Portuguese National Institute of Health (1990-2004).Euro Surveill. 2006;11(10):257-60.PMID: 17130658

22. Mygland A, Ljøstad U, Fingerle V, Rupprecht T, Schmutzhard E, Steiner I. EFNS guidelines on the diagnosis and management of European Lyme neuroborreliosis. Eur J Neurol. 2010;17(1):8-16, e1-4. DOI: 10.1111/j.1468-1331.2009.02862.x PMID: 19930447

23. Paradowska-Stankiewicz I, Chrześcijańska I. Lyme disease in Poland in 2012.Przegl Epidemiol. 2014;68(2):275-7, 375-7.PMID: 25135514

24. Dryden MS, Saeed K, Ogborn S, Swales P. Lyme borreliosis in southern United Kingdom and a case for a new syndrome, chronic arthropod-borne neuropathy. Epidemiol Infect. 2015;143(3):561-72. DOI: 10.1017/S0950268814001071 PMID: 24814098

25. Leeflang MM, Ang CW, Berkhout J, Bijlmer HA, Van Bortel W, Brandenburg $A H$, et al. The diagnostic accuracy of serological tests for Lyme borreliosis in Europe: a systematic review and meta-analysis. BMC Infect Dis. 2016;16(1):140. DOI: 10.1186/ S12879-016-1468-4 PMID: 27013465

26. Rizzoli A, Hauffe H, Carpi G, Vourc HG, Neteler M, Rosa R. Lyme borreliosis in Europe.Euro Surveill. 2011;16(27):19906.PMID: 21794218

27. Muller I, Freitag MH, Poggensee G, Scharnetzky E, Straube $\mathrm{E}$, Schoerner C, et al. Evaluating frequency, diagnostic quality, and cost of Lyme borreliosis testing in Germany: a retrospective model analysis. Clin Dev Immunol. 2012;2012:595427. DOI: 10.1155/2012/595427

28. Dehnert M, Fingerle V, Klier C, Talaska T, Schlaud M, Krause $G$, et al. Seropositivity of Lyme borreliosis and associated risk factors: a population-based study in Children and Adolescents in Germany (KiGGS). PLoS One. 2012;7(8):e41321. DOI: 10.1371/ journal.pone.0041321 PMID: 22905101

29. Kiewra D, Zaleśny G. Relationship between temporal abundance of ticks and incidence of Lyme borreliosis in Lower Silesia regions of Poland.J Vector Ecol. 2013;38(2):345-52. DOI: 10.1111/j.1948-7134.2013.12050.x PMID: 24581365

30. Schwarz A, Hönig V, Vavrušková Z, Grubhoffer L, Balczun C, Albring $A$, et al. Abundance of Ixodes ricinus and prevalence of Borrelia burgdorferi s.l. in the nature reserve Siebengebirge, Germany, in comparison to three former studies from 1978 onwards. Parasit Vectors. 2012;5(1):268. DOI: 10.1186/17563305-5-268 PMID: 23171708

31. van den Wijngaard CC, Hofhuis A, Harms MG, Haagsma JA, Wong A, de Wit GA, et al. The burden of Lyme borreliosis expressed in disability-adjusted life years. Eur J Public Health. 2015;25(6):1071-8. DOI: 10.1093/eurpub/ckv091 PMID: 26082446

32. van den Wijngaard CC, Hofhuis A, Wong A, Harms MG, de Wit $\mathrm{GA}$, Lugnér AK, et al. The cost of Lyme borreliosis. Eur J Public Health. 2017;27(3):538-47. DOI: 10.1093/eurpub/ckw269 PMID: 28444236

33. European Centre for Disease Prevention and Control (ECDC), European Food Safety Authority (EFSA). VectorNet: A European network for sharing data on the geographic distribution of arthropod vectors, transmitting human and animal disease agents. Stockholm: ECDC. [Accessed 27 Dec 2016]. Available from: http://ecdc.europa.eu/en/healthtopics/vectors/ VectorNet/Pages/VectorNet.aspx

34. Wormser GP, Dattwyler RJ, Shapiro ED, Halperin JJ, Steere AC, Klempner MS, et al. The clinical assessment, treatment, and prevention of lyme disease, human granulocytic anaplasmosis, and babesiosis: clinical practice guidelines by the Infectious Diseases Society of America. Clin Infect Dis. 2006;43(9):1089134. DOI: 10.1086/508667 PMID: 17029130

35. Kullberg BJ, Berende A, van der Meer JW. The challenge of Lyme disease: tired of the Lyme wars. Neth J Med. 2011;69(3):98-100. PMID: 21444933

36. Berende A, ter Hofstede HJ, Donders AR, van Middendorp $\mathrm{H}$, Kessels RP, Adang EM, et al. Persistent Lyme Empiric Antibiotic Study Europe (PLEASE)--design of a randomized controlled trial of prolonged antibiotic treatment in patients with persistent symptoms attributed to Lyme borreliosis. BMC Infect Dis. 2014;14(1):543. DOI: 10.1186/s12879-014-0543-y PMID: 25318999

37. Berende A, ter Hofstede HJ, Vos FJ, van Middendorp H, Vogelaar ML, Tromp M, et al. Randomized Trial of Longer-Term Therapy for Symptoms Attributed to Lyme Disease. N Engl J Med. 2016;374(13):1209-20. DOI: 10.1056/NEJMoa1505425 PMID: 27028911

38. World Health Organization (WHO). Immunization, Vaccines and Biologicals. Sentinel Surveillance Geneva: WHO. [Accessed 27
Dec 2016]. Available from: http://www.who.int/immunization/ monitoring surveillance/burden/vpd/surveillance_type/ sentinel/en/

39. Krause G, Ropers G, Stark K. Notifiable disease surveillance and practicing physicians. Emerg Infect Dis. 2005;11(3):442-5. DOI: 10.3201/eid1103.040361 PMID: 15757561

40. Jelastopulu E, Merekoulias G, Alexopoulos EC. Underreporting of communicable diseases in the prefecture of Achaia, western Greece, 1999-2004 - missed opportunities for early intervention.Euro Surveill. 2010;15(21):19579.PMID: 20519103

41. Richard JL, Vidondo B, Mäusezahl M. A 5-year comparison of performance of sentinel and mandatory notification surveillance systems for measles in Switzerland.Eur J Epidemiol. 2008;23(1):55-65. DOI: 10.1007/s10654-007-9187-1 PMID: 17899399

42. Gibbons CL, Mangen MJ, Plass D, Havelaar AH, Brooke RJ, Kramarz $\mathrm{P}$, et al. Measuring underreporting and underascertainment in infectious disease datasets: a comparison of methods. BMC Public Health. 2014;14(1):147. DOI: 10.1186/1471-2458-14-147 PMID: 24517715

43. Braks M, Medlock JM, Hubalek Z, Hjertqvist M, Perrin Y, Lancelot $R$, et al. Vector-borne disease intelligence: strategies to deal with disease burden and threats. Front Public Health. 2014;2:280. DOI: 10.3389/fpubh.2014.00280 PMID: 25566522

\section{License and copyright}

This is an open-access article distributed under the terms of the Creative Commons Attribution (CC BY 4.0) Licence. You may share and adapt the material, but must give appropriate credit to the source, provide a link to the licence, and indicate if changes were made.

This article is copyright of the authors, 2017. 